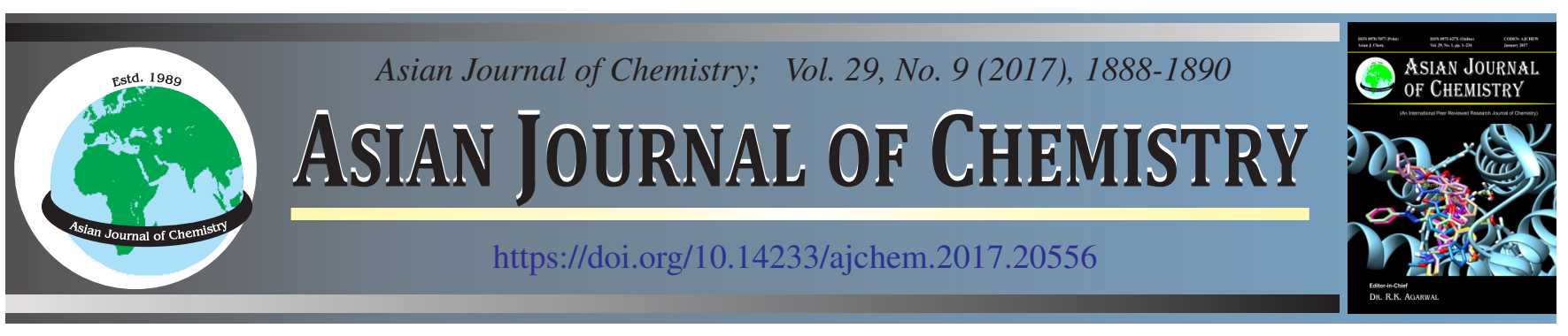

\title{
Effect of Pyridine and Tribenzylamine on the Hydrolysis Kinetics of Benzoyl Chloride in Water-Dioxane System
}

\author{
Mohammad A. Batiha ${ }^{1, *}$, Elena A. Chizhova ${ }^{2}$, Marwan M. Batiha ${ }^{1}$, Leema A. Al-Makhadmeh ${ }^{1}$, \\ Saleh Rawadieh ${ }^{1}$, Muawia Alqasaimeh ${ }^{3}$ and Abdullah Marashli ${ }^{1}$
}

${ }^{1}$ Faculty of Engineering, Al-Hussein Bin Talal University, 71111 Ma'an, Jordan

${ }^{2}$ Ivanovo State University of Chemistry and Technology, 153000, Ivanovo, Russia

${ }^{3}$ Faculty of Science, Al-Hussein Bin Talal University, 71111 Ma'an, Jordan

*Corresponding author: E-mail: mbatiha@ahu.edu.jo

The aim of this paper was to study the effect of tribenzylamine and pyridine on the kinetics of the hydrolysis reaction of benzoyl chloride in water-dioxane solution. The benzoyl chloride and water initial concentrations were 0.005 and $1 \mathrm{~mol} / \mathrm{L}$, respectively. While, the initial concentrations of pyridine and tribenzylamine varied in the range of $0.005-0.02 \mathrm{~mol} / \mathrm{L}$ and $0.007-0.014 \mathrm{~mol} / \mathrm{L}$, respectively. It was found that the addition of tribenzylamine to benzoyl chloride hydrolysis reaction has no catalytic effect and hence the rate constant can be calculated using a first-order rate equation. In the presence of pyridine, reaction obeyed second-order rate. The relationship between the reaction rate constant and pyridine initial concentration was found to be linear with a rate constant of $0.752 \times 10^{-3} \mathrm{~min}^{-1}$.

Keywords: Benzoyl chloride, Hydrolysis kinetics, Tertiary amines, Tribenzylamine, Water-dioxane solutions.

\section{INTRODUCTION}

Since the first article published in 1927 by Berger and Olivier for acyl chlorides hydrolysis study, many studies were published including benzoyl chloride hydrolysis as acyl chloride. Diefallah et al. [1] studied the hydrolysis reaction of benzoyl chloride in series ratios mixtures of iso-propyl alcohol with water. They found a strong relationship between the observed rate constant and the solvent composition.

A study of the reaction of glycine and benzoyl chloride in an alkaline aqueous solution/dichloromethane two-phase medium under inverse phase transfer catalysis was conducted by Wang et al. [2]. The reaction was described by a pseudofirst-order rate law. When the concentration of benzoyl chloride was increased, the reaction rate decreases.

A kinetic study of reactions of aniline and benzoyl chloride using ammonia as acid absorbent in a micro structured chemical system was conducted by Wang et al. [3]. They found that the reaction time is reduced by $99 \%$ when ammonia was used compared to condition without ammonia. Many kinetic studies were also published for the hydrolysis of substituted benzoyl chlorides. For examples, the hydrolysis of substituted benzoyl chlorides in the presence of: $\alpha-, \beta$ - and $\gamma$-cyclodextrin were studied by Bascuas et al. [4], hexafluoroisopropanolwater by Bascuas et al. [5], acetic and formic acids by Bentley and Harris [6] and fluoro alcohols or 1,1,1,3,3,3-hexafluoro2-propanol by Kevill and D'souza [7].

The hydrolysis kinetic studies of acyl chlorides involving benzoyl chloride are necessary owing to the highly reactive acyl chloride, as unique monomers, in approaches of synthesizing polymers [8]. In previous study, the effect of pyridine, 2-methyl pyridine, 3-methyl pyridine, 2,6-dimethyl pyridine, quinoline and tribenzylamine on the hydrolysis kinetics of benzoyl chloride in water-dioxane solutions was studied [9]. The strongest catalytic effect on the hydrolysis reaction of benzoyl chloride was for pyridine and 3-methyl pyridine, while the weakest effect was for quinoline. In this paper, the effect of pyridine and tribenzylamine on the hydrolysis kinetics of benzoyl chloride in water-dioxane solutions was investigated.

\section{EXPERIMENTAL}

The kinetic reaction:

$$
\mathrm{C}_{6} \mathrm{H}_{5} \mathrm{COCl}+\mathrm{H}_{2} \mathrm{O} \longrightarrow \mathrm{C}_{6} \mathrm{H}_{5} \mathrm{COOH}+\mathrm{HCl}
$$

was carried out in water-dioxane solution at $25 \pm 0.01{ }^{\circ} \mathrm{C}$. Pyridine and tribenzylamine were used as a tertiary amine in reaction (I). Benzoyl chloride, pyridine and tribenzylamine were purified according to methods described in Ivanova et al. [10], while dioxane was purified according to Vorobuv and Shebanova [11]. Double distilled water was used in this study. 
The first distillation was carried out by adding $\mathrm{KMnO}_{4}\left(\mathrm{~T}_{\mathrm{b}}=\right.$ $99.8^{\circ} \mathrm{C}$ at $\mathrm{P}=756 \mathrm{~mm} \mathrm{Hg}$ ).

In all experiments, only freshly prepared dioxane and water were used. Methods of kinetic experiments and analysis of the reaction mixture were the same as reported by Ivanova et al. [10]. In all the experiments, the initial concentration of benzoyl chloride was taken to be $0.005 \mathrm{~mol} / \mathrm{L}$ and the initial concentration of water was $1 \mathrm{~mol} / \mathrm{L}$. The initial concentrations of pyridine and tribenzylamine were varied in the range of 0.005-0.02 $\mathrm{mol} / \mathrm{L}$ and 0.007-0.014 mol/L, respectively.

\section{RESULTS AND DISCUSSION}

The observed reaction rate constant $\left(\mathrm{k}_{1}\right)$ for reaction (I) carried out in the presence of pyridine was calculated using the equation:

$$
\mathrm{k}_{1}=\frac{1}{\tau\left(\mathrm{C}_{0, \mathrm{~b}}-\mathrm{C}_{0, \mathrm{p}}\right)} \ln \frac{\mathrm{C}_{0, \mathrm{p}}\left(\mathrm{C}_{0, \mathrm{~b}}-\mathrm{x}\right)}{\mathrm{C}_{0, \mathrm{~b}}\left(\mathrm{C}_{0, \mathrm{p}}-\mathrm{x}\right)}
$$

where $\mathrm{C}_{0, \mathrm{~b}}$ and $\mathrm{C}_{0, \mathrm{p}}$ are the initial concentration of benzoyl chloride and pyridine, respectively; $\mathrm{x}$ is the change in benzoyl chloride concentration at time $\mathrm{t}$ from the start of the reaction.

It was found that the hydrolysis of benzoyl chloride in an aqueous solution in the presence of pyridine obeys secondorder rate reaction. It was established experimentally that when calculating according to eqn. 1 , the rate constants values retain their constancy to the degree of conversion equal to 60-70\%. Table- 1 lists the arithmetic means of the observed rate constant $\left(\mathrm{k}_{1}\right)$ for a concentration of benzoyl chloride of $0.005 \mathrm{~mol} / \mathrm{L}$ and different initial concentrations of pyridine in the reaction mixture.

TABLE-1

OBSERVED REACTION RATE CONSTANTS FOR THE HYDROLYSIS REACTION OF BENZOYL CHLORIDE IN DIOXANE CONTAINING $1 \mathrm{~mol} / \mathrm{l} \mathrm{mol}$ OF WATER AT $25^{\circ} \mathrm{C}$

\begin{tabular}{ccc}
\hline \multicolumn{2}{c}{ Initial concentration $(\mathrm{mol} / \mathrm{L})$} & \multirow{2}{*}{$\mathrm{k}_{1}(\mathrm{~L} / \mathrm{mol} \mathrm{min})$} \\
\cline { 1 - 2 } Benzoyl chloride & Pyridine & $1.28 \pm 0.09$ \\
0.005 & 0.0050 & $1.27 \pm 0.09$ \\
0.005 & 0.0075 & $1.25 \pm 0.09$ \\
0.005 & 0.0100 & $1.28 \pm 0.06$ \\
0.005 & 0.0050 & $1.19 \pm 0.03$ \\
0.005 & 0.0150 & $1.24 \pm 0.06$ \\
0.005 & 0.0200 & $1.25 \pm 0.07$ \\
\hline \multicolumn{3}{c}{ Average } \\
\hline
\end{tabular}

When tribenzylamine $(\mathrm{C}=0.007 \pm 0.014 \mathrm{~mol} / \mathrm{L})$ was added to the reaction mixture, the observed rate constant was calculated using the following first-order reaction rate equation:

$$
\mathrm{k}_{2}=\frac{1}{2} \ln \frac{\mathrm{C}_{0, \mathrm{~b}}}{\mathrm{C}_{\mathrm{b}}}
$$

Table-2 lists the values of $\mathrm{k}_{1}$ and $\mathrm{k}_{2}$ for the hydrolysis reaction of benzoyl chloride in the presence of pyridine and tribenzylamine. The initial concentrations of water and benzoyl chloride were 1.000 and $0.005 \mathrm{~mol} / \mathrm{L}$, respectively.

From Table-2, it follows that the addition of tribenzylamine did not affect the hydrolysis reaction of benzoyl chloride; it only binds $\mathrm{HCl}$ released during the reaction. From the results listed in Table-2, the rate constants for the hydrolysis reaction without catalyst were calculated as:
TABLE-2

RATE CONSTANTS $k_{1}$ AND $k_{2}$ FOR THE HYDROLYSIS REACTION OF BENZOYL CHLORIDE IN PRESENCE

\begin{tabular}{|c|c|c|c|c|}
\hline \multicolumn{2}{|c|}{ Initial concentration $(\mathrm{mol} / \mathrm{L})$} & \multirow{2}{*}{$\begin{array}{c}\mathrm{k}_{1}(\mathrm{~L} / \mathrm{mol} \\
\mathrm{min})\end{array}$} & \multirow{2}{*}{$\begin{array}{l}\mathrm{k}_{2} \times 10^{3} \\
\left(\min ^{-1}\right)\end{array}$} & \multirow{2}{*}{$\mathrm{k}_{2} / \mathrm{C}_{0, \mathrm{p}}$} \\
\hline Pyridine & Tribenzylamine & & & \\
\hline 0.0050 & 0.007 & 1.28 & 6.45 & 1.29 \\
\hline 0.0075 & 0.014 & 1.27 & 8.11 & 1.08 \\
\hline 0.0100 & 0.014 & 1.25 & 12.44 & 1.24 \\
\hline 0.0150 & 0.014 & 1.19 & 16.28 & 1.09 \\
\hline 0.0200 & 0.014 & 1.24 & 22.96 & 1.15 \\
\hline \multicolumn{2}{|c|}{ Average } & 1.25 & 13.25 & 1.17 \\
\hline
\end{tabular}
OF PYRIDINE AND TRIBENZYLAMINE

$$
\mathrm{k}_{\mathrm{obs}}=\mathrm{k}_{1}{ }^{\prime}+\mathrm{k}_{2}{ }^{\prime} \mathrm{C}_{0, \mathrm{p}}
$$

where $\mathrm{k}_{1}{ }^{\prime}$ is the rate constant for non-catalytic reduction stage of the process of hydrolysis of benzoyl chloride; and $\mathrm{k}_{2}$ ' is the rate constant for the catalyzed stage by pyridine.

The dependence of $\mathrm{k}_{1}$ on the initial concentration of pyridine is shown in Fig. 1. The relationship is linear and $\mathrm{k}_{1}$ is $0.752 \times 10^{-3} \mathrm{~min}^{-1}$, as it was defined in previous work [12].

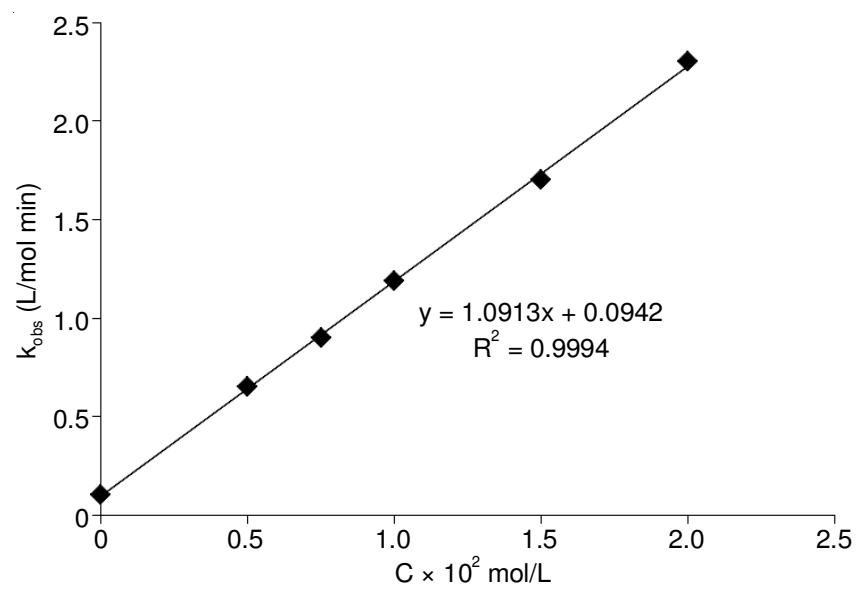

Fig. 1. Dependence of $k_{1}$ on the initial concentration of pyridine

The results confirm that reaction (I) obeys the first order kinetic law. Experiments showed that the addition of tribenzylamine has no catalytic effect on the studied reaction and rate constant in this case can be calculated using a first-order equation. If pyridine is used as a tertiary amine, then, as can be seen from reaction (I), hydrogen chloride released during reaction process is bound to pyridine hydrochloride and the concentration of pyridine in the reaction mixture varies over time.

In this paper, preliminary kinetic study showed that during hydrolysis process of benzoyl chloride, the released benzoic acid and pyridine hydrochloride acid have no effect on the rate of the studied reaction.

It is well known that the hydrolysis reaction of benzoyl chloride in aqueous solution proceeds slowly [10,12] and in the studied concentration range its rate can be neglected in comparison with the rate of catalytic hydrolysis reaction in the presence of pyridine.

\section{Conclusion}

The effect of tribenzylamine and pyridine on the hydrolysis kinetics of benzoyl chloride in water-dioxane solutions was investigated successfully. In the presence of pyridine, reaction 
obeys second-order rate. The addition of tribenzylamine did not affect the hydrolysis reaction of benzoyl chloride; it only binds $\mathrm{HCl}$ released during the reaction. The dependence of $\mathrm{k}_{1}$ on the initial concentration of pyridine was $0.752 \times 10^{-3} \mathrm{~min}^{-1}$. Kinetic study showed that during hydrolysis process of benzoyl chloride, the released benzoic acid and pyridine hydrochloride acid have no effect on the rate of the studied reaction.

\section{REFERENCES}

1. El-Hussieny M. Diefallah, M.A. Mousa, M.A. Ashy and S.A. Ghonaim, Z. Phys. Chem., 115, 89 (1979); https://doi.org/10.1524/zpch.1979.115.1.089.

2. M.-L. Wang, C.-C. Ou and J.-J. Jwo, Chem. Eng. Commun., 179, 233 (2000);

https://doi.org/10.1080/00986440008912198.

3. P. Wang, J. Zhang, K. Wang, G. Luo and P. Xie, Ind. Eng. Chem. Res., 55, 6310 (2016); https://doi.org/10.1021/acs.iecr.6b00506.
4. J. Báscuas, L. Garcia-Rio and J.R. Leis, Org. Biomol. Chem., 2, 1186(2004); https://doi.org/10.1039/B400302K.

5. J. Báscuas, L. García-Río, J.R. Leis and M. Méndez-Pérez, J. Incl. Phenom. Macrocycl. Chem., 57, 603 (2007); https://doi.org/10.1007/s10847-006-9276-x.

6. T.W. Bentley and H.C. Harris, Int. J. Mol. Sci., 12, 4805 (2011); https://doi.org/10.3390/ijms12084805.

7. D.N. Kevill and M.J. D'Souza, J. Phys. Org. Chem., 15, 881 (2002); https://doi.org/10.1002/poc.569.

8. S.G. Éntelis, R.P., Tiger, E.Ya. Nevel'skiiand I.V. Épel'baum, Russ. Chem. Bull., 12, 223 (1963); https://doi.org/10.1007/BF00846386

9. M.A. Batiha, E.A. Chizhova and M.M. Batiha, Asian J. Chem., 25, 4087 (2013); https://doi.org/10.14233/ajchem.2013.14238.

10. N.S. Ivanovo, N.K. Vorobuv and G.V. Kulikova, Problems Kinetics Catal., 5, 33 (1979).

11. N.K. Vorobuv and O.K. Shebanova, Chem. Chem. Technol., 17, 688 (1974).

12. O.K. Shebanovo, E.A. Chizhova and E.V. Kulibaba, Chem. Chem. Technol., 18, 709 (1975). 